\title{
Early Antiretroviral Therapy in HIV-Infected Children Is Associated with Diffuse White Matter Structural Abnormality and Corpus Callosum Sparing
}

(D) C. Ackermann, (D) Andronikou, (D) M.G. Saleh, (D) B. Laughton, (D)A.A. Alhamud, (D) A. van der Kouwe, (D) M. Kidd,

(D) M.F. Cotton, and (DE.M. Meintjes

\begin{abstract}
BACKGROUND AND PURPOSE: Fractional anisotropy in the frontal white matter, corpus callosum, and internal capsule is abnormal in human immunodeficiency virus-positive (HIV + ) adults. We describe the distribution and nature of white matter abnormalities in a cohort of children who started antiretroviral therapy within the first year of life and the benefit of early treatment by using DTI measures (fractional anisotropy and mean, axial, and radial diffusion).
\end{abstract}

MATERIALS AND METHODS: DTI was performed on children in a neurodevelopmental substudy from the Children with HIV Early Antiretroviral trial. Voxel-based group comparisons were obtained to determine regions where fractional anisotropy and mean diffusion differed between HIV + and uninfected children. Associations of DTI parameters with the timing of antiretroviral therapy initiation were examined.

RESULTS: Thirty-nine HIV + children ( 15 boys; mean age, 5.4 years) and 13 controls ( 5 boys; mean age, 5.7 years) were scanned. Two clusters with lower fractional anisotropy and 7 clusters with increased mean diffusion were identified in the HIV + group, with symmetric distribution predominantly due to increased radial diffusion, suggestive of decreased myelination. Corticospinal tracts rather than the corpus callosum were predominantly involved. Children on early-interrupted antiretroviral therapy had lower fractional anisotropy compared with those receiving continuous treatment.

CONCLUSIONS: HIV + children at 5 years of age have white matter abnormalities measured by fractional anisotropy, despite early antiretroviral therapy, suggesting that early antiretroviral therapy does not fully protect the white matter from either peripartum or in utero infection. In contrast to adults, the corticospinal tracts are predominantly involved rather than the corpus callosum, possibly due to early antiretroviral therapy. Continuous early antiretroviral therapy can limit white matter damage.

ABBREVIATIONS: $A D=$ axial diffusivity; ART = antiretroviral therapy; $C C=$ corpus callosum; CHER $=$ Children with HIV Early Antiretroviral trial; CST = corticospinal tract; $\mathrm{FA}$ = fractional anisotropy; $\mathrm{HIV}=$ human immunodeficiency virus; HIV + = human immunodeficiency virus-positive; $\mathrm{MD}=$ mean diffusivity; $\mathrm{RD}=$ radial diffusivity

W hite matter structural abnormalities can be assessed by using quantitative parameters determined from DTI. ${ }^{1}$ Fractional anisotropy (FA) provides information about the microstructural integrity of highly oriented microstructures but is not specific to

Received April 5, 2016; accepted after revision July 4.

From the Departments of Radiodiagnosis (C.A.) and Paediatrics and Child Health (B.L., M.F.C.), Faculty of Medicine and Health Sciences, and Centre for Statistical Consultation (M.K.), Stellenbosch University, Tygerberg, South Africa; Clinical Research and Imaging Centre, Bristol (S.A.), University of Bristol, Bristol, UK; Department of Paediatric Radiology (S.A.), Bristol Royal Hospital for Children, Bristol, UK; Department of Human Biology (M.G.S., A.A.A., E.M.M.), Medical Research Council/ University of Cape Town Medical Imaging Research Unit, University of Cape Town, Cape Town, South Africa; and Athinoula A. Martinos Center for Biomedical Imaging (A.v.d.K.), Massachusetts General Hospital, Charlestown, Massachusetts. This work was supported by grants from the Harry Crossley Foundation, the South African Medical Research Council, the National Research Foundation grant CPR20110614000019421, the South African National Research Foundation/Department of Science and Technology South African Research Chairs Initiative, the National Institute of Allergy and Infectious Diseases through the Comprehensive the type of injury. Mean diffusivity (MD) is a measure of average molecular motion independent of any tissue directionality.

Loss of axonal integrity decreases FA and increases MD; however, increased FA may also indicate loss of complexity in the underlying axonal matrix due to loss of crossing and other nonparallel fibers. Increased radial diffusivity (RD), a marker of excessive axonal packing attenuation and/or poor myelination, ${ }^{2}$ and

International Program of Research on AIDS network, grant U19 AI53217, and the National Institutes of Health R01 HD071664 and R21MH096559.

The content is solely the responsibility of the authors and does not necessarily represent the official views of the National Institutes of Health.

Paper previously presented as a digital poster and preliminary findings at: European Society of Pediatric Radiology Annual Congress, June 2-6, 2014; Amsterdam, the Netherlands.

Please address correspondence to Christelle Ackermann, MD, Kanonnier Crescent 27, Kanonberg, Bellville, 7530, Cape Town, South Africa; e-mail: ca@sun.ac.za

- Indicates open access to non-subscribers at www.ajnr.org

http://dx.doi.org/10.3174/ajnr.A4921 
decreased axial diffusivity (AD), an index of axonal damage, occur in human immunodeficiency virus (HIV)-associated WM injury. ${ }^{3-5} \mathrm{FA}$ in the frontal subcortical WM, corpus callosum (CC), and internal capsule is abnormal in HIV-positive (HIV+) adults. ${ }^{6-8}$ Those with the most advanced HIV disease have the highest diffusion constant elevations and the largest anisotropy reductions, specifically in the CC and frontal WM. ${ }^{6}$ Most early studies used a priori ROI analyses. Subsequently, more widespread WM damage has been shown by using voxelwise and whole-brain analyses. ${ }^{1,3,7,9,10}$ Animal neuro-AIDS models also show WM damage: Macaques show reduced FA in the CC genu, ${ }^{11}$ and mice have reduced FA (mainly due to increased RD) and increased MD in the CC. ${ }^{12}$

Few studies have used DTI to examine HIV-associated alterations in WM in children. Lower FA and higher MD and RD in the $\mathrm{CC}$ and higher MD in the superior longitudinal fasciculus have been demonstrated in antiretroviral therapy (ART)-naïve children (8-12 years of age) compared with age-matched controls, ${ }^{13}$ while ART failure was associated with decreased FA in the left superior and right posterior corona radiata and decreased $\mathrm{AD}$ in the left inferior cerebellar peduncle in 50 children on first-line ART (6-15 years of age). ${ }^{14}$ Regional and whole-brain decreases in FA and increased MD and RD, compared with controls, have been reported in HIV+ children and adolescents (6-20 years of age), ${ }^{15,16}$ irrespective of treatment status. ${ }^{15}$ Regional alterations were related to past disease severity, measured by nadir CD $4 \%$, and peak viral loads. ${ }^{16}$ ART-naïve children (6-11 years of age) showed reduced myelin compared with children on ART (6-16 years of age) but were also younger. ${ }^{15}$ These studies did not document ART history.

Adolescents stable on ART ( $n=15,13-17$ years of age; mean age at ART initiation, 9.5 years) had lower FA in the CC, superior and posterior corona radiata, frontal and parietal WM, pre- and postcentral gyrus, and superior longitudinal fasciculus (mainly due to increased RD) than controls $(n=26) .{ }^{17}$

Despite consistent evidence of HIV-related WM alterations, studies have included wide age ranges over developmental phases when both WM volume and FA demonstrates notable increase. ${ }^{18-20}$ Few studies have controlled adequately for age or ART regimens. To date, no DTI studies have been performed in younger children, and none, in children receiving standardized early ART (within the first year of life), to our knowledge.

The aim of the present study was to determine the spatial distribution and nature of WM abnormalities at 5 years of age in a cohort of HIV + children beginning ART well within the first year of life. An additional aim was to explore the association of the timing of ART initiation and DTI-derived parameters (FA, AD, $\mathrm{RD})$, to interrogate the potential protection of early ART on WM microstructures.

We hypothesized poorer WM integrity when starting ART after 12 weeks of age.

\section{MATERIALS AND METHODS \\ Subjects}

We present data for 52 of 62 children enrolled in a neurodevelopmental substudy of the Children with HIV Early Antiretroviral (CHER) trial ${ }^{21,22}$ in Cape Town, South Africa. The group com- prised HIV + children on ART and age-matched controls from a parallel vaccine study, with informed consent from parents or caregivers. $^{23}$

Exclusions were the following: $6 \mathrm{HIV}+$ subjects with mixed ancestry (the genetic determinants of ethnicity could influence brain growth and maturity and we felt that having a more homogeneous study population and control group would remove bias), $1 \mathrm{HIV}+$ child whose structural image was motion-corrupted, 1 control child with incidental periventricular leukoencephalopathy, and 2 HIV + children with data intersection instabilities.

The CHER trial was a 2-center study in which HIV + infants between 6 and 12 weeks of age and CD $4 \geq 25 \%$ were randomized to 1 of 3 treatment strategies: ART-deferred until indicated, earlylimited ART for 40 weeks, and early-limited ART for 96 weeks. Infants with a $\mathrm{CD} 4 \%<25 \%$ were enrolled into a separate group (Part B), initially to be randomized into ART for 40 weeks and ART for 96 weeks but then retained on early-continuous ART. The entire cohort comprised $451 \mathrm{HIV}$-infected infants younger than 12 weeks of age. Four hundred eleven infants had baseline CD4 $\geq 25 \%$, of whom 377 were reported in the main trial. ${ }^{22}$

Continuous ART was initiated in the ART-Deferred arm when the CD4 declined below 25\% in the first year of life and 20\% thereafter or for the Centers for Disease Control severe stage B or $\mathrm{C}$ disease. These criteria also applied to restarting ART in the ART for 40 weeks and ART for 96 weeks arms. Because some children in ART-Deferred began ART early, we stratified children into those starting ART after (late ART) or before 12 weeks (early ART), irrespective of the treatment arm. In addition, because some in the ART for 40 weeks and ART for 96 weeks arms met the end points during primary therapy, the early ART group was subdivided into those with or without treatment interruption.

First-line ART was lopinavir-ritonavir, lamivudine, and zidovudine. Most mothers had participated in the prevention of mother-to-child transmission program, which included zidovudine antenatally from 32 weeks and single-dose nevirapine at delivery. Mothers with a CD 4 count below 250 cells per cubic millimeter received ART antenatally. Neonates received a single dose of nevirapine at birth and zidovudine for 7 days.

Children were in regular follow-up with 3 monthly clinical assessments.

Baseline laboratory and clinical data at enrollment and within 6 months of MR imaging scan, including CD4, CD8 parameters, and viral load, were obtained from participant medical records and the CHER data base. A viral load of $>750,000$ copies/mL was assigned as 750,001, and that with $<400$ copies/mL, as 399 (viral suppression).

Ethics approval for the study was obtained from ethics boards of all institutions involved.

\section{MR Imaging Data Acquisition}

The children were imaged on a 3T MR imaging scanner by using structural T1 imaging followed by 2 DTI acquisitions with opposite phase-encoding directions by using a twice-refocused spin-echo sequence. ${ }^{24}$ The $3 \mathrm{D}$ EPI-navigated ${ }^{25}$ multiecho $^{2}$ MPRAGE $^{26}$ sequence was acquired in a sagittal orientation with the following parameters: FOV $=224 \times 224 \mathrm{~mm}, 144$ sections, $\mathrm{TR}=2530 \mathrm{~ms}, \mathrm{TE}=1.53 / 3.19 / 4.86 / 6.53 \mathrm{~ms}, \mathrm{TI}=1160 \mathrm{~ms}$, flip 
Table 1: Sample characteristics of HIV-infected children ${ }^{\text {a }}$

\begin{tabular}{lcccc}
\hline & $\begin{array}{c}\text { Late ART } \\
(>12 \text { wk) }\end{array}$ & $\begin{array}{c}\text { Early ART } \\
(<12 \text { wk) } \\
\text { Interrupted }\end{array}$ & $\begin{array}{c}\text { Early ART } \\
(<12 \text { wk) Not } \\
\text { Interrupted }\end{array}$ & $\begin{array}{c}P \\
\text { Value }\end{array}$ \\
\hline No. & 13 & 16 & 10 & \\
Sex & $4 \mathrm{M} / 9 \mathrm{~F}$ & $5 \mathrm{M} / 11 \mathrm{~F}$ & $6 \mathrm{M} / 4 \mathrm{~F}$ & .30 \\
Age at scan (yr) & $5.3(0.30)$ & $5.4(0.24)$ & $5.6(0.43)$ & .20 \\
Age ART started (wk) & $36(17)$ & $8(2)$ & $8(2)$ & $<.01^{\mathrm{b}}$ \\
Time on ART (wk) & $241(22)$ & $203(59)$ & $285(22)$ & $<.01^{\mathrm{b}}$ \\
Time interrupted (wk) & $\mathrm{NA}$ & $85(90)$ & $\mathrm{NA}$ & \\
Clinical measures at baseline & & & & \\
CD4 count & $2064(711)$ & $1969(1118)$ & $1720(978)$ & .57 \\
CD4\% & $37(7)$ & $35(10)$ & $30(13)$ & .21 \\
CD8 count & $1751(1109)$ & $1460(675)$ & $1978(945)$ & .34 \\
VL $>750,000(\%)($ No.) & $69(9)$ & $56(9)$ & $40(4)$ & .37 \\
$400<$ VL $<750,000(\%)$ (No.) & $31(4)$ & $44(7)$ & $60(6)$ & \\
Clinical measures within 6 mo of scan & $1027(392)$ & $1110(460)$ & $1289(592)$ & .58 \\
CD4 count & $37(8)$ & $34(7)$ & $36(10)$ & .49 \\
CD4\% & $902(450)$ & $1083(544)$ & $1087(625)$ & .57 \\
CD8 count & $8(1)$ & 0 & 0 & .14 \\
VL $>750,000(\%)($ No.) & $23(3)$ & $6(1)$ & 0 & \\
$400<$ VL $<750,000(\%)$ (No.) & $69(9)$ & $94(15)$ & $100(10)$ & \\
Suppressed VL (\%) (No.) & & & & \\
\hline Not & & &
\end{tabular}

Note:-NA indicates not applicable; VL, viral load.

${ }^{\text {a }}$ Values are mean (SD).

b Significant.

${ }^{c}$ Calculated up to the time of scanning in 3 children who had not restarted ART.

angle $=7^{\circ}$, voxel size $=1.3 \times 1.0 \times 1.0 \mathrm{~mm}^{3}$. DWI was performed in 30 directions with $b=1000 \mathrm{~s} / \mathrm{mm}^{2}$, voxel size $=2 \times 2 \times$ $2 \mathrm{~mm}^{3}, \mathrm{TR} / \mathrm{TE}=9500 / 86 \mathrm{~ms}$, and 4 volumes with $b=0 \mathrm{~s} / \mathrm{mm}^{2}$.

\section{Data Analysis}

Preprocessing. Diffusion-weighted volumes with signal dropout or motion-corrupted sections were removed, ${ }^{27}$ and the diffusion-encoding scheme was adjusted, with a constraint that the same volumes be removed in both DTI acquisitions. Coregistration and susceptibility correction were performed. ${ }^{28,29}$ Briefly, coregistration of individual volumes to the first unweighted image was performed by using linear affine (12 df) transformation (FMRIB Linear Image Registration Tool, FLIRT; http://www. fmrib.ox.ac.uk/) in FSL (http://www.fmrib.ox.ac.uk/fsl). Subsequently, these images were imported to Matlab (MathWorks, Natick, Massachusetts) for susceptibility correction and outlier rejection. ${ }^{29}$ Outliers of each acquisition were examined by first calculating $z$ scores on the basis of 25 and 75 percentile limits; data points above 3 SDs beyond the mean were discarded. The 2 acquisitions were combined into a single corrected image; FA, MD, and eigenvalue $\left(e_{1}, e_{2}\right.$, and $\left.e_{3}\right)$ images were generated. The first eigenvalue $\left(e_{1}\right)$ was $A D$; the remaining 2 were used to compute $\mathrm{RD}\left(\mathrm{e}_{23}=\left[\mathrm{e}_{2}+\mathrm{e}_{3}\right] / 2\right)$.

Coregistration. The FA images were first coregistered to corresponding structural images to achieve intrasubject alignment. Structural images of all subjects were then coregistered to a "most representative" control image; then they were subsequently coregistered to the National Institutes of Health pediatric MRI Data Repository T1-template image for children 4.5-8.5 years of age, with an isotropic resolution of $1.0 \times 1.0 \times 1.0 \mathrm{~mm}^{3}$ by using linear (FLIRT) and nonlinear (FMRIB Nonlinear Registration Tool, FNIRT; http://fsl.fmrib.ox.ac.uk/fsl/fslwiki/FNIRT) coregistration algorithms in FSL. ${ }^{30} \mathrm{FA}$ images were warped by using the same transforms for intersubject alignment. The same transforms were applied to $\mathrm{MD}, \mathrm{AD}$, and RD images. A WM binary mask was generated for each subject by applying an FA threshold of 0.2. Individual masks were multiplied to generate a final binary image representing $\mathrm{WM}$ regions with $\mathrm{FA} \geq 0.2$ in all subjects. The binary image was multiplied by the coregistered FA and MD images of each subject to localize statistical analyses, explained below, to the same WM regions.

Statistical Analysis. Voxel-based group comparisons were performed in FSL to determine regions where $\mathrm{FA}$ and $\mathrm{MD}$ differed significantly between HIV+ and control children and between $\mathrm{HIV}+$ children starting ART late or early and those with and without interruption. To account for multiple comparisons when determining significant clusters, we used the AlphaSim command (http://afni.nimh.nih.gov/pub/dist/doc/program_help/AlphaSim. html) in Analysis of Functional Neuro Images (AFNI; http://afni. nimh.nih.gov/afni) with an overall significance level of $\alpha=.05$ and an individual voxelwise significance level of $P=.01$. Full width at half maximum values ranged between 3.8 and $5.2 \mathrm{~mm}$ across the masked thresholded WM masks, and we performed 5000 Monte Carlo simulations. ${ }^{31}$ Clusters of at least $258 \mathrm{~mm}^{3}$ were significant at these levels.

Locations of clusters showing group differences were identified by using the Harvard-Oxford cortical and subcortical and Johns Hopkins University WM tractography atlases provided in FSL and an MR imaging atlas of human WM anatomy. ${ }^{32,33}$ For each cluster, average FA and $\mathrm{MD}$ and corresponding $\mathrm{AD}$ and $\mathrm{RD}$ values were extracted.

Categoric variables were summarized by using frequency and percentage of frequency distributions overall and by group. Continuous measurements were summarized by using means and SDs. Variables were compared between the groups by using ANOVA and $\chi^{2}$ tests.

\section{RESULTS}

After exclusions, we present data for 13 healthy controls (mean age, $5.7 \pm 0.5$ years; 5 boys) and $39 \mathrm{HIV}+$ children (mean age, $5.4 \pm 0.3$ years; 15 boys). Demographic and clinical data of HIV + children are presented in Table 1.

Ten children receiving early ART fulfilled the criteria for continuous ART. ART in 16 children was interrupted after primary therapy, and 3 had not restarted ART by the time of MR imaging. Parents of 1 child randomized to ART at 96 weeks initially withheld ART without knowledge of the investigators. This child was included in the late-treatment group.

Four children started ART under Part B; treatments of 2 were interrupted, and 2 were on continuous ART.

AJNR Am J Neuroradiol 37:2363-69 Dec 2016 www.ajnr.org 
Table 2: Clusters in which FA was lower in HIV+ children compared with controls ${ }^{\mathrm{a}}$

\begin{tabular}{|c|c|c|c|c|c|c|c|c|}
\hline \multirow{2}{*}{$\begin{array}{c}\text { Cluster } \\
\text { Location/CST }\end{array}$} & \multirow{2}{*}{$\begin{array}{c}\text { Size } \\
\left(\mathrm{mm}^{3}\right)\end{array}$} & \multirow[b]{2}{*}{ Coordinates } & \multicolumn{3}{|c|}{$A D$} & \multicolumn{3}{|c|}{ RD } \\
\hline & & & HIV+ & Control & $P$ Value & HIV+ & Control & $P$ Value \\
\hline Right internal capsule & 365 & $27,-23,-1$ & $1.18(0.03)$ & $1.20(0.03)$ & .10 & $0.60(0.10)$ & $0.56(0.02)$ & $<.001$ \\
\hline Right parietal lobe & 294 & $19,-24,42$ & $1.18(0.06)$ & $1.22(0.07)$ & .08 & $0.60(0.04)$ & $0.56(0.03)$ & $<.001$ \\
\hline
\end{tabular}

a values are mean (SD).

Table 3: Clusters in which HIV + children had significantly greater MD compared with controls ${ }^{\mathrm{a}}$

\begin{tabular}{|c|c|c|c|c|c|c|c|c|}
\hline \multirow[b]{2}{*}{ Cluster Location } & \multirow{2}{*}{$\begin{array}{c}\text { Size } \\
\left(\mathrm{mm}^{3}\right)\end{array}$} & \multirow[b]{2}{*}{ Coordinates } & \multicolumn{3}{|c|}{$A D$} & \multicolumn{3}{|c|}{ RD } \\
\hline & & & Control & HIV+ & $P$ Value & Control & HIV+ & $P$ Value \\
\hline \multicolumn{9}{|l|}{ ILF/SLF } \\
\hline Right temporal & 7503 & $32,0,-24$ & $1.19(0.03)$ & $1.23(0.03)$ & .001 & $0.62(0.02)$ & $0.65(0.03)$ & $<.001$ \\
\hline Left putamen & 6916 & $-29,-26,-2$ & $1.20(0.03)$ & $1.25(0.03)$ & .001 & $0.59(0.02)$ & $0.62(0.03)$ & $<.001$ \\
\hline \multicolumn{9}{|l|}{ CST } \\
\hline Right brain stem & 916 & $21,-15,-9$ & $1.25(0.04)$ & $1.29(0.03)$ & .01 & $0.58(0.02)$ & $0.63(0.02)$ & $<.001$ \\
\hline \multicolumn{9}{|l|}{ IFOF } \\
\hline Left temporal & 555 & $-37,-10,-17$ & $1.19(0.05)$ & $1.25(0.04)$ & .003 & $0.66(0.02)$ & $0.70(0.04)$ & $<.001$ \\
\hline \multicolumn{9}{|l|}{ Forceps minor } \\
\hline Left frontal & 336 & $-19,43,14$ & $1.20(0.06)$ & $1.24(0.06)$ & .04 & $0.63(0.03)$ & $0.67(0.05)$ & .0030 \\
\hline Left frontal & 266 & $-17,42,-1$ & $1.22(0.06)$ & $1.26(0.06)$ & .05 & $0.62(0.03)$ & $0.65(0.05)$ & .0040 \\
\hline \multicolumn{9}{|l|}{ UF } \\
\hline Right frontal & 330 & $15,38,-12$ & $1.19(0.05)$ & $1.25(0.06)$ & .003 & $0.64(0.03)$ & $0.67(0.04)$ & .0046 \\
\hline
\end{tabular}

Note:-ILF/SLF indicates inferior/superior longitudinal fasciculus; IFOF, inferior fronto-occipital fasciculus; UF, uncinate fasciculus.

a Values are mean (SD).

The cumulative period on ART was longest for those receiving early-continuous ART.

Eighty-seven percent $(n=34)$ had viral load suppression $(<400$ copies $/ \mathrm{mL})$. Of the $13 \%(n=5)$ unsuppressed at MR imaging, 4 were in the late-ART group (with viral load of 3590, 5980, 8870 , and $>750,000$ HIV RNA copies/mL) and 1 was in the early ART-interrupted group (204,000 HIV RNA copies/mL).

\section{Imaging}

On the T1-weighted MR images, structural abnormalities were identified in 3 HIV + children (mild cerebellar atrophy, mild generalized atrophy, pineal multilobed cyst), and none in controls.

Two clusters were identified in the right corticospinal tract (CST), where FA was lower in HIV + children than in controls (mean FA, $0.42 \pm 0.03$ versus $0.46 \pm 0.03$; and $0.43 \pm 0.04$ versus $0.49 \pm 0.04)$. Differences in FA were attributable to increased RD $(P<.001$, Table 2). Left-sided similar clusters were seen, however, not surviving cluster-size correction. The FA and RD values in these clusters for the child with viral load $>750,000$ HIV RNA copies/mL at scan were below the group average (excluding this child) but not the lowest overall. FA values did not differ significantly between the other 4 unsuppressed children and the remaining group.

Seven clusters showed higher MD at $P<.01$ in infected children than in controls, the largest being $7503 \mathrm{~mm}^{3}$, which included several tracts. Both $\mathrm{AD}$ and $\mathrm{RD}$ contributed to the increased MD (Table 3).

\section{Comparison of FA between Children Starting ART before and after 12 Weeks of Age}

Against our hypothesis, children starting ART later did not demonstrate poorer white matter integrity as measured by FA. Rather, 1 cluster was identified in the brain stem in the left CST, where FA was lower in early compared with late ART initiation. When comparing early-continuous and early-interrupted ART individually against late ART, we found lower FA only in the early-interrupted ART group, suggesting that interruption is harmful to WM. No regions showed FA differences between early-continuous and late ART. The reduced FA in the children on early-interrupted ART was attributable to increased $\mathrm{RD}$ and $\mathrm{AD}$.

\section{DISCUSSION}

We demonstrated WM areas with significantly reduced FA in $\mathrm{HIV}+$ children initiating ART at a median age of 4 months compared with uninfected controls.

\section{No Frontal or Parietal White Matter Predilection for Abnormal Findings}

Our findings confirm the presence of FA abnormalities found in $\mathrm{HIV}+$ adults and adolescents but differ in volume and distribution. Young children on early ART had very few regions with abnormal FA. The predilection for frontal lobe involvement described in adults ${ }^{34-38}$ was not seen possibly due to the small sample size, specifically the control group $(n=13)$. We previously reported multifocal WM signal abnormalities on standard T2weighted MR imaging sequences in frontal (91\%) and parietal WM $(82 \%)$ of HIV + children at a mean age 31.9 months. ${ }^{39}$ Twenty of these children are also included in the present study. Ten had WM signal abnormality on FLAIR. ${ }^{39}$ Unfortunately, a limitation in the present study was the absence of FLAIR, thus an inability to assess interval WM signal change. However, the absence of frontal and parietal involvement in FA does suggest interval improvement on ART.

Although clusters showing left-sided FA differences did not survive cluster-size correction, FA reductions were bilateral in the CST. The MD differences were more widely distributed and included the inferior longitudinal fasciculus (bilateral), CST, inferior fronto-occipital fasciculus, forceps minor, and uncinate fasciculus. 
Because frontal WM myelination continues into adulthood, children demonstrate inherently lower frontal FA values than adults. ${ }^{40}$ To exclude frontal predominance of WM abnormality being maturational, ${ }^{41}$ we determined areas of significant FA difference between HIV + children and age-matched controls by using voxelwise group comparisons. The predominant contribution to decreased FA was RD, while the increased MD was due to both $\mathrm{RD}$ and $\mathrm{AD}$, indicating both reduced myelin and loss of axonal integrity. ${ }^{42}$

The age difference between the HIV + and control groups was only a few months, not considered clinically significant. Our study has a much narrower age range than previous studies, facilitating improved comparison with controls representing the agerelated normally developing brain.

\section{Children's Ages and ART Relevance}

The higher FA values in those beginning ART after 12 weeks was surprising because we expected this finding in those beginning ART before 12 weeks. However, the difference was attributable to ART interruption, possibly negating the benefits of early ART, rather than neurotoxicity due to longer ART exposure. ${ }^{43-45}$

The timing of the interruption may be important with reference to WM maturation. Three phases of maturation are observed by FA: rapid change in the first 3-6 months, slower change until 24 months, and relative stability thereafter. Most WM tracts are formed at birth; then they increase in size together with FA during 24 months. ${ }^{46}$ Deep WM structures such as the CC and internal capsule have high FA at birth, which rapidly rises. In contrast, frontal WM has low FA, increasing to intermediate values around 24 months. In neonates, the CST is present within the brain stem, but the size and intensity are much lower than in the older brain. ${ }^{47}$ Postmortem studies, however, have shown that the CST and the superior cerebellar peduncles mature early. ${ }^{48,49}$ ART was interrupted at 40 weeks (around 10 months of age); this interruption may have coincided with a critical stage of CST maturation.

Notably, we found no CC involvement in HIV+ children. HIV-associated FA abnormalities in the CC have been reported in adults and in children. ${ }^{6,7,8,13}$ In contrast, our children started ART early compared with those in other studies. Most interesting, CC volume and thickness were similar to those in controls in a study by Andronikou et al, ${ }^{50}$ which included the $20 \mathrm{HIV}+$ children previously reported. The CC genu demonstrates a variable growth spurt at 2 months of age, followed by similar growth in the splenium by $4-6$ months, with myelination being visible on T1weighted MR imaging from 4-6 months. ${ }^{51}$ Our data support early ART being neuroprotective for the CC.

That no FA differences were noted between the late and earlycontinuous groups may have been a "survivor effect." Eight children in the ART-Deferred arm died in the first year of life and were not studied. In addition, those on early-continuous rather than early-limited ART were more severely affected by HIV, having already reached a trial end point during primary ART, thus being ineligible for interruption. All participants on continuous therapy had suppressed viral loads at the time of scanning. Notably, those from Part B had a baseline CD4 below 25\% and therefore had more advanced HIV. Nevertheless, the early-interrupted children had the most WM damage, suggesting that WM is more vulnerable at the time that ART interruption occurred.

Our data strongly suggest that WM damage, though not prevented by early ART, can be ameliorated or reversed, possibly through reduced neuroinflammation. ${ }^{52}$ The children in this study are enrolled in a longitudinal neuroimaging study that includes DTI at age 7 and 9 years, which will provide vital information on the continuous effect of ART and/or HIV as well as answer questions relating to the influence of white matter maturation.

\section{CONCLUSIONS}

$\mathrm{HIV}+$ children at 5 years of age have WM fiber abnormalities measured by FA despite early ART, suggesting that early ART does not fully protect the WM from either peripartum or in utero infection. In contrast to adults, the CSTs of children are predominantly involved rather than the CC, possibly due to early ART. Continuous ART can limit WM damage.

\section{ACKNOWLEDGMENTS}

We thank GlaxoSmithKline/ViiVplc Healthcare and the Departments of Health of the Western Cape and Gauteng for supporting the CHER trial.

Disclosures: Barbara Laughton—RELATED: Grant: National Institutes Of Health,* Comments: R01 HD071664-01: Longitudinal Neuroimaging and Cognitive Study of HIV-Infected Children. I am a co-Principal Investigator on this study. The grant was awarded to Massachusetts General Hospital, and Stellenbosch University has a subcontract. Andre van der Kouwe-RELATED: Grant: National Institutes of Health,* Comments: National Institutes of Health National Institute of Child Health and Human Development R01 HD071664; this grant supports the published work in part; Support for Travel to Meetings for the Study or Other Purposes: National Institutes of Health, ${ }^{*}$ Comments: National Institutes of Health National Institute of Child Health and Human Development R01 HD071664; this grant supports travel to achieve the aims of the grant, which, in part, supports the published work; UNRELATED: Grants/Grants Pending: National Institutes of Health,* Bertarelli Foundation,* Travel/Accommodations/Meeting Expenses Unrelated to Activities Listed: $\mathrm{Na}$ tional Institutes of Health,* Bertarelli Foundation.* Mark F. Cotton—RELATED: Grant: National Institutes of Health, ${ }^{*}$ Comments: grant U19 Al53217 for the CHER trial; Provision of Materials: ViiVplc Healthcare, Comments: supply of zidovudine and lamivudine. Ernesta M. Meintjes-RELATED: Grant: National Institutes of Health,* National Research Foundation of South Africa.* *Money paid to the institution.

\section{REFERENCES}

1. Stebbins GT, Smith CA, Bartt RE, et al. HIV-associated alterations in normal-appearing white matter: a voxel-wise diffusion tensor imaging study. J Acquir Immune Defic Syndr 2007;46:564-73 CrossRef Medline

2. Beaulieu C. The basis of anisotropic water diffusion in the nervous system: a technical review. NMR Biomed 2002;15:435-55 CrossRef Medline

3. Leite SC, Corrêa DG, Doring TM, et al. Diffusion tensor MRI evaluation of the corona radiata, cingulate gyri, and corpus callosum in HIV patients. J Magn Reson Imaging 2013;38:1488-93 CrossRef Medline

4. Hoare J, Ransford GL, Phillips N, et al. Systematic review of neuroimaging studies in vertically transmitted HIV positive children and adolescents. Metab Brain Dis 2014;29:221-29 CrossRef Medline

5. Alexander AL, Lee JE, Lazar M, et al. Diffusion tensor imaging of the brain. Neurotherapeutics 2007;4:316-29 CrossRef Medline

6. Filippi CG, Ulug AM, Ryan E, et al. Diffusion tensor imaging of patients with HIV and normal-appearing white matter on MR images of the brain. AJNR Am J Neuroradiol 2001;22:277-83 Medline

7. Gongvatana A, Schweinsburg BC, Taylor MJ, et al. White matter tract injury and cognitive impairment in human immunodefi- 
ciency virus-infected individuals. J Neurovirol 2009;15:187-95 CrossRef Medline

8. Pomara N, Crandall DT, Choi SJ, et al. White matter abnormalities in HIV-1 infection: a diffusion tensor imaging study. Psychiatry Res 2001;106:15-24 CrossRef Medline

9. Stubbe-Drger B, Deppe M, Mohammadi S, et al; German Competence Network HIV/AIDS. Early microstructural white matter changes in patients with HIV: a diffusion tensor imaging study. BMC Neurol 2012;12:23 CrossRef Medline

10. Gongvatana A, Cohen RA, Correia S, et al. Clinical contributors to cerebral white matter integrity in HIV-infected individuals. J Neurovirol 2011;17:477-86 CrossRef Medline

11. Li C, Zhang X, Komery A, et al. Longitudinal diffusion tensor imaging and perfusion MRI investigation in a macaque model of neuroAIDS: a preliminary study. Neuroimage 2011;58:286-92 CrossRef Medline

12. Lentz MR, Peterson KL, Ibrahim WG, et al. Diffusion tensor and volumetric magnetic resonance measures as biomarkers of brain damage in a small animal model of HIV. PLoS One 2014;9:e105752 CrossRef Medline

13. Hoare J, Fouche JP, Spottiswoode B, et al. A diffusion tensor imaging and neurocognitive study of HIV-positive children who are HAART-naive "slow progressors." J Neurovirol 2012;18:205-12 CrossRef Medline

14. Hoare J, Fouche JP, Phillips N, et al. Clinical associations of white matter damage in cART-treated HIV-positive children in South Africa. J Neurovirol 2015;21:120-28 CrossRef Medline

15. Hoare J, Fouche JP, Phillips N, et al. White matter micro-structural changes in ART-naive and ART-treated children and adolescents infected with HIV in South Africa. AIDS 2015;29:1793-801 CrossRef Medline

16. Uban KA, Herting MM, Williams PL, et al; Pediatric HIVAIDS Cohort and the Pediatric Imaging, Neurocognition, and Genetics Studies. White matter microstructure among youth with perinatally acquired HIV is associated with disease severity. AIDS 2015;29: 1035-44 CrossRef Medline

17. $\mathrm{Li} \mathrm{J}, \mathrm{Wu} \mathrm{Z}$, Wen $\mathrm{Z}$, et al. White matter development is potentially influenced in adolescents with vertically transmitted HIV infections: a tract-based spatial statistics study. AJNR Am J Neuroradiol 2015;36: 2163-69 CrossRef Medline

18. Barnea-Goraly N, Menon V, Eckert M, et al. White matter development during childhood and adolescence: a cross-sectional diffusion tensor imaging study. Cereb Cortex 2005;15:1848-54 CrossRef Medline

19. Giedd JN, Blumenthal J, Jeffries NO, et al. Brain development during childhood and adolescence: a longitudinal MRI study. Nat Neurosci 1999;2:861-63 CrossRef Medline

20. Brouwer RM, Mandl RCW, Schnack HG, et al. White matter development in early puberty: a longitudinal volumetric and diffusion tensor imaging twin study. PLoS One 2012;7:e32316 CrossRef Medline

21. Violari A, Cotton MF, Gibb DM, et al; CHER Study Team. Early antiretroviral therapy and mortality among HIV-infected infants. N Engl J Med 2008;359:2233-44 CrossRef Medline

22. Cotton MF, Violari A, Otwombe K, et al; CHER Study Team. Early time-limited antiretroviral therapy versus deferred therapy in South African infants infected with HIV: results from the children with HIV early antiretroviral (CHER) randomised trial. Lancet 2013;382:1555-63 CrossRef Medline

23. Madhi S, Adrian P, Cotton M, et al; Comprehensive International Program of Research on AIDS 4 Study Team. Effect of HIV infection status and anti-retroviral treatment on quantitative and qualitative antibody responses to pneumococcal conjugate vaccine in infants. J Infect Dis 2010;202:355-61 CrossRef Medline

24. Reese TG, Heid O, Weisskoff RM, et al. Reduction of eddy-currentinduced distortion in diffusion MRI using a twice-refocused spin echo. Magn Reson Med 2003;49:177-82 CrossRef Medline

25. Tisdall MD, Hess AT, Reuter M, et al. Volumetric navigators for prospective motion correction and selective reacquisition in neuroanatomical MRI. Magn Reson Med 2012;68:389-99 CrossRef Medline

26. van der Kouwe AJ, Benner T, Salat DH, et al. Brain morphometry with multiecho MPRAGE. Neuroimage 2008;40:559-69 CrossRef Medline

27. Tournier JD, Mori S, Leemans A. Diffusion tensor imaging and beyond. Magn Reson Med 2011;65:1532-56 CrossRef Medline

28. Jenkinson M, Bannister P, Brady M, et al. Improved optimization for the robust and accurate linear registration and motion correction of brain images. Neuroimage 2002;17:825-41 CrossRef Medline

29. Andersson JL, Skare S, Ashburner J. How to correct susceptibility distortions in spin-echo echo-planar images: application to diffusion tensor imaging. Neuroimage 2003;20:870-88 CrossRef Medline

30. Fonov V, Evans AC, Botteron K, et al; Brain Development Cooperative Group. Unbiased average age-appropriate atlases for pediatric studies. Neuroimage 2011;54:313-27 CrossRef Medline

31. Forman SD, Cohen JD, Fitzgerald M, et al. Improved assessment of significant activation in functional magnetic resonance imaging (fMRI): use of a cluster-size threshold. Magn Reson Med 1995;33: 636-47 CrossRef Medline

32. Mori S, Wakana S, Van Zijl PC, et al. MRI Atlas of Human White Matter. Amsterdam: Elsevier; 2005

33. Peters B, Szeszko P, Radua J, et al. White matter development in adolescence: diffusion tensor imaging and meta-analytic results. Schizophr Bul .2012:38:1308-17 CrossRef Medline

34. Ragin $\mathrm{AB}, \mathrm{Wu} \mathrm{Y}$, Storey $\mathrm{P}$, et al. Diffusion tensor imaging of subcortical brain injury in patients infected with human immunodeficiency virus. J Neurovirol 2005;11:292-98 CrossRef Medline

35. Thurnher MM, Castillo M, Stadler A, et al. Diffusion-tensor MR imaging of the brain in human immunodeficiency virus-positive patients. AJNR Am J Neuroradiol 2005;26:2275-81 Medline

36. Wu Y, Storey $\mathrm{P}$, Cohen BA, et al. Diffusion alterations in corpus callosum of patients with HIV. AJNR Am J Neuroradiol 2006;27: 656-60 Medline

37. Pfefferbaum A, Rosenbloom MJ, Rohlfing T, et al. Frontostriatal fiber bundle compromise in HIV infection without dementia. AIDS 2009;23:1977-85 CrossRef Medline

38. Chen $\mathrm{Y}, \mathrm{An} \mathrm{H}, \mathrm{Zhu} \mathrm{H}$, et al. White matter abnormalities revealed by diffusion tensor imaging in non-demented and demented HIV+ patients. Neuroimage 2009;47:1154-62 CrossRef Medline

39. Ackermann C, Andronikou S, Laughton B, et al. White matter signal abnormalities in children with suspected HIV-related neurologic disease on early combination antiretroviral therapy. Pediatr Infect Dis J 2014;33:e207-12 CrossRef Medline

40. Klingberg T, Vaidya CJ, Gabrieli JD, et al. Myelination and organization of the frontal white matter in children: a diffusion tensor MRI study. Neuroreport 1999;10:2817-21 CrossRef Medline

41. Snook L, Paulson LA, Roy D, et al. Diffusion tensor imaging of neurodevelopment in children and young adults. Neuroimage. 2005;26: 1164-73 CrossRef Medline

42. Song S, Sun S, Ramsbottom M, et al. Dysmyelination revealed through MRI as increased radial (but unchanged axial) diffusion of water. Neuroimage 2002;17:1429-36 CrossRef Medline

43. Cicarelli N, Fabbiani M, Di Giambenedetto S, et al. Efavirenz associated with cognitive disorders in otherwise asymptomatic HIV-infected patients. Neurology 2011;76:1403-09 CrossRef Medline

44. Abers MS, Shandera WX, Kass JS. Neurological and psychiatric adverse effects of antiretroviral drugs. CNS Drugs 2014;28:131-45 CrossRef Medline

45. Tardieu M, Brunelle F, Raybaud, et al. Cerebral MR imaging in uninfected children born to HIV-seropositive mothers and perinatally exposed to zidovudine. AJNR Am J Neuroradiol 2005:26:695701 Medline

46. Huang $\mathrm{H}$, Zhang J, Wakana S, et al. White and gray matter development in human fetal, newborn and pediatric brains. Neuroimage 2006;33:27-38 CrossRef Medline

47. Hermoye L, Saint-Martin C, Cosnard G, et al. Pediatric diffusion 
tensor imaging: normal database and observation of the white matter maturation in early childhood. Neuroimage 2006;29:493-504 CrossRef Medline

48. Brody BA, Kinney HC, Kloman AS, et al. Sequence of central nervous system myelination in human infancy, I: an autopsy study of myelination. J Neuropathol Exp Neurol 1987;46:283-301 CrossRef Medline

49. Kinney HC, Brody BA, Kloman AS, et al. Sequence of central nervous system myelination in human infancy, II: patterns of myelination in autopsied infants. J Neuropathol Exp Neurol 1988;47:217-34 CrossRef Medline
50. Andronikou S, Ackermann C, Laughton B, et al. Corpus callosum thickness on mid-sagittal MRI as a marker of brain volume: a pilot study in children with HIV-related brain disease and controls. $P e$ diatr Radiol 2015;45:1016-25 CrossRef Medline

51. Barkovich AJ, Kjos BO. Normal postnatal development of the corpus callosum as demonstrated by MR imaging. AJNR Am J Neuroradiol 1988;9:487-91 Medline

52. Wright PW, Heaps JM, Shimony JS, et al. The effects of HIV and combination antiretroviral therapy on white matter integrity. AIDS 2012;26:1501-08 CrossRef Medline 